\title{
PROYEKSI KEBUTUHAN DAN PENYEDIAAN ENERGI LISTRIK DI KABUPATEN KUNINGAN MENGGUNAKAN PERANGKAT LUNAK LEAP DENGAN METODE END USE
}

\author{
Gugun Muliawandana ${ }^{1}$, Edvin Priatna $^{2}$, Ifkar Usrah ${ }^{3}$ \\ Teknik Elektro, Fakultas Teknik, Universitas Siliwangi ${ }^{123}$ \\ email: gugunmuliawandana@ student.unsil.ac.id $^{1}$
}

\begin{abstract}
The need for electricity continues to grow every year. It can be ascertained that the growth of a modern society, the electrical energy needs in general will increase in proportion to the level of economic activity and also the population in the region. This condition must be anticipated as early as possible so that the availability of electrical energy can be available in sufficient quantities.

This final project research was made to determine the needs and supply of electricity from 2018 to 2022 in Kuningan Regency. Electric energy projection uses LEAP (Long-range Energy Alternatives Planning) software as a projection process. The end use method is a detailed calculation of the use of electricity by each customer built on the basis of data and analysis of end use in each sector using electricity, the target to be projected is the number of customers of electricity, and electricity consumption.

The results of this thesis research for the projection of the number of customers of electrical energy and the amount of electrical energy demand in Kuningan Regency continue to show an increase, from 2018 with a total of 191,343 customers to 219,327 customers in 2022 with an average growth of the number of customers of electricity $54 \%$ every year. And the amount of electrical energy consumption in Kuningan Regency also continues to show an increase from 2018 with a total of 29,353,007,476.40 $\mathrm{kWh}$ to 60,840,484,844.50 kWh in 2022 with an average growth of electricity consumption of $8.88 \%$ annually.
\end{abstract}

Keywords: LEAP, End Use Method, Customer, Projection, Consumption

\begin{abstract}
Abstrak
Kebutuhan akan energi listrik terus bertumbuh setiap tahunnya. Dapat dipastikan bahwa pertumbuhan suatu masyarakat modern, kebutuhan energi listrik pada umumnya akan meningkat sebanding dengan tingkat aktifitas ekonomi dan juga jumlah penduduk dalam wilayah tersebut. Kondisi ini tentunya harus diantisipasi sedini mungkin agar ketersediaan energi listrik dapat tersedia dalam jumlah yang cukup. Penelitian tugas akhir ini dibuat untuk mengetahui kebutuhan dan penyediaan energi listrik dari tahun 2018 sampai dengan 2022 di Kabupaten Kuningan. Proyeksi energi listrik menggunakan perangkat lunak LEAP (Long-range Energy Alternatives Planning) sebagai proses proyeksi. Metode end use adalah perhitungan secara rinci pemakaian tenaga listrik oleh setiap pelanggan yang dibangun berdasarkan data dan analisa penggunaan akhir pada setiap sektor pemakai energi listrik, sasaran yang akan diproyeksikan adalah jumlah pelanggan energi listrik, dan konsumsi energi listrik.

Hasil penelitian tugas akhir ini untuk proyeksi jumlah pelanggan energi listrik dan jumlah kebutuhan energi listrik di Kabupaten Kuningan terus menunjukan adanya peningkatan yaitu dari tahun 2018 dengan total 191.343 pelanggan menjadi 219.327 pelanggan di tahun 2022 dengan pertumbuhan rata-rata jumlah pelanggan energi listrik adalah sebesar 1,54\% tiap tahunnya. Dan jumlah konsumsi energi listrik di Kabupaten Kuningan juga terus menunjukan adanya peningkatan dari tahun 2018 dengan total 29.353.007.476,40 kWh menjadi $60.840 .484 .844,50 \mathrm{kWh}$ di tahun 2022 dengan pertumbuhan rata-rata konsumsi energi listrik adalah sebesar 8,88\% tiap tahunnya.
\end{abstract}

Kata Kunci: LEAP, Metode End Use, Pelanggan, Proyeksi, Konsumsi.

\section{PENDAhULUAN}

Kebutuhan akan energi listrik terus bertumbuh setiap tahunnya. Dapat dipastikan bahwa pertumbuhan suatu masyarakat modern, kebutuhan energi listrik pada umumnya akan meningkat sebanding dengan tingkat aktifitas ekonomi dan juga jumlah penduduk dalam wilayah tersebut [1].

Kabupaten Kuningan berada di Provinsi Jawa Barat, dengan Laju Pertumbuhan Penduduk (LPP) yang mencapai 0,59\% di tahun 2017 menurut Badan Pusat Statistik berbagai perkembangan di Kabupaten Kuningan baik dibidang perekonomian, infrastruktur, industri, kesehatan dan pendidikan begitu sangat pesat. Begitu juga energi listrik sangat dibutuhkan oleh warga Kabupaten Kuningan, pada tahun 2017 penjualan energi listrik PT PLN (Persero) Kabupaten Kuningan mencapai 19.133.913.882 kWh untuk 241.099 pelanggan, jumlah pelanggan yang bisa terlayani terbagi menjadi beberapa kategori yaitu, sosial, rumah tangga, bisnis, industri, dan pemerintahan.

\section{KAJIAN PUSTAKA}

A. Proyeksi Kebutuhan Energi Listrik

Dalam buku yang ditulis oleh AS Pabla, Ir. Abdul Hadi $(1994,86)$ dijelaskan bahwa perencanaan untuk sistem daya optimum dapat dibagi menjadi tiga macam yaitu:

1) Prakiraan jangka panjang

Pada perencanaan sistem distribusi jangka panjang biasanya termasuk (tahun horison) dua belas tahun atau lebih sebelum saat sekarang.

2) Prakiraan jangka menengah

Jangka waktu untuk perencanaan jangka menengah ini antara tiga tahun sampai dua belas tahun, kebanyakan metode ekonomi untuk mengembangkan jaringan telah termasuk dalam parameter- parameter pada jangka panjang yang membahas pengembangan sistem dengan cara-cara lebih umum

3) Prakiraan jangka pendek

Prakiraan jangka pendek atau rencana taktis memerlukan periode satu sampai tiga tahun di muka dan 
biasanya hanya merupakan pelaksanaan hasil studi jangka panjang [2].

B. Fakto-faktor Yang Mempengaruhi Tingkat Kebutuhan Energi Listrik

Penggunaan tenaga listrik diperkirakan akan selalu meningkat setiap tahunnya. Hal ini dikarenakan oleh semakin berkembangnya kebutuhan masyarakat yang harus dipenuhi. Menurut tingkat kebutuhan energi listrik dipengaruhi oleh faktor -faktor berikut ini:

1) Faktor ekonomi yang mempengaruhi tingkat kebutuhan tenaga listrik adalah pertumbuhan PDRB (Produk Domestik Regional Bruto), Secara umum, PDRB dapat dibagi menjadi 3 sektor, yaitu PDRB sektor komersial (bisnis), sektor industri dan sektor publik. Kegiatan ekonomi yang dikategorikan sebagai sektor komersial/bisnis adalah sektor listrik, gas dan air bersih, bangunan dan konstruksi, perdagangan, serta transportasi dan komunikasi. Kegiatan ekonomi yang termasuk sektor publik adalah jasa dan perbankan, termasuk lembaga keuangan selain perbankan. Sektor Industri sendiri adalah mencakup kegiatan industri migas dan manufaktur.

2) Faktor pertumbuhan penduduk memiliki pengaruh besar terhadap kebutuhan tenaga listrik selain faktor ekonomi. Sesuai dengan prinsip demografi, pertumbuhan penduduk akan terus turun setiap tahunnya sampai pada suatu saat akan berada pada kondisi yang stabil.

3) Faktor pembangunan daerah. Berjalannya pembangunan daerah akan sangat dipengaruhi oleh tingkat perekonomian daerah itu sendiri. Dalam hal ini baik langsung maupun tidak langsung, faktor ekonomi sangat berpengaruh terhadap kebutuhan energi listrik seiring dengan berjalannya pembangunan [3].

C. Produk Domestik Regional Bruto

Merupakan nilai tambah bruto seluruh barang dan jasa yang tercipta atau dihasilkan di wilayah domestik suatu negara yang timbul akibat berbagai aktivitas ekonomi dalam suatu periode tertentu tanpa memperhatikan apakah faktor produksi yang dimiliki residen atau non-residen [4].

D. Elastisitas

Elastisitas permintaan tenaga listrik yaitu perbandingan pertumbuhan penjualan energi listrik $(\mathrm{kWh})$ dengan pertumbuhan ekonomi (PDRB) [5].

\section{E. Faktor Pelanggan}

Faktor pelanggan yaitu perbandingan antara jumlah pelanggan dengan pertumbuhan ekonomi (PDRB) [5].

F. Intensitas Energi

Intensitas pemakaian energi adalah parameter yang menyatakan besarnya pemakaian energi untuk melakukan suatu aktivitas tertentu. Intensitas pemakaian energi yaitu daya yang terjual (Kosumsi Energi Listrik) dan aktifitas (Jumlah Pelanggan Energi Listrik) [5].

\section{G. Metode Perkiraan Perencanaan Energi}

Ada berbagai model pendekatan untuk menyusun prakiraan kebutuhan tenaga listrik yang tersedia antara lain pendekatan ekonometrik, pendekatan proses, pendekatan time series, pendekatan end-use, pendekatan trend maupun gabungan dari berbagai model pendekatan perencanaan. Dari beberapa metode tersebut, yang sering digunakan sebagai pendekatan untuk proyeksi kebutuhan energi listrik adalah metode pendekatan ekonometri dan pendekatan end-use.
Perbedaan dari kedua metode tersebut adalah pada jenis data masukan [5].

\section{H. Metode End Use}

Metode end-use juga dikenal sebagai pendekatan engineering model. Pendekatan ini akan lebih detail walaupun secara perhitungan menggunakan fungsi yang lebih sederhana. Pertimbangan teknologi yang digunakan dalam proses aliran energi juga menjadi variabel perhitungan. Pendekatan ini sangat cocok untuk keperluan proyeksi efisiensi energi karena dimungkinkan untuk secara eksplisit mempertimbangkan perubahan teknologi dan tingkat pelayanan[5].

Berikut ini adalah Persaman Matematika metode End Use:

1) Jumlah Pelanggan

$$
N C_{r(t)}=\left(\left(\frac{R E_{(t)}}{100}\right)\left(\frac{J P_{(t)}}{(P / H h)_{(t)}}\right) 100\right)
$$

Dimana:

$N C_{r(t)}=$ Jumlah pelanggan rumah tangga tahun t (Jiwa);

$t \quad=$ Tahun;

$R E_{(t)} \quad=$ Rasio elektrifikasi tahun $\mathrm{t}$;

$J P_{t} \quad=$ Jumlah penduduk tahun $\mathrm{t}$;

$(P / H h)_{(t)}=$ Jumlah orang per rumah tangga tahun.

$N C_{I(t)}=\left(1+\left(\frac{\left(C F_{I(t)} / G D_{I(t)}\right.}{100}\right)\right) N C_{I(t-1)}$

$N C_{I(t)} \quad=\quad$ Jumlah pelanggan industri tahun $\mathrm{t}$ (jiwa);

$C F_{I(t)}=$ kapasitas pelanggan sektor industri tahun $\mathrm{t}$;

$G D_{I(t)}=$ Pertumbuhan PDRB sektor industri tahun $\mathrm{t}(\%)$.

$N C_{B(t)}=\left(1+\left(\frac{\left(C F_{B(t)} / G D_{B(t)}\right.}{100}\right)\right) N C_{B(t-1)}$

$N C_{B(t)}=$ Jumlah pelanggan bisnis tahun $\mathrm{t}$ (jiwa);

$C F_{B(t)}=$ kapasitas pelanggan sektor bisnis tahun $\mathrm{t}$;

$G D_{B(t)}=$ Pertumbuhan PDRB sektor bisnis tahun $\mathrm{t}(\%)$.

$N C_{S(t)}=\left(1+\left(\frac{\left(C F_{S(t)} / G D_{S(t)}\right.}{100}\right)\right) N C_{S(t-1)}$

$N C_{S(t)} \quad=\quad$ Jumlah pelanggan sosial tahun $\mathrm{t}$ (jiwa);

$C F_{S(t)} \quad=\quad$ kapasitas pelanggan sektor sosial tahun t;

$G D_{S(t)} \quad=\quad$ Pertumbuhan PDRB sektor sosial tahun $\mathrm{t}(\%)$.

$N C_{P(t)}=\left(1+\left(\frac{\left(C F_{P(t)} / G D_{P(t)}\right.}{100}\right)\right) N C_{P(t-1)}$

$N C_{P(t)}=$ Jumlah pelanggan Pemerintah tahun $\mathrm{t}$ (jiwa);

$C F_{P(t)}=$ kapasitas pelanggan sektor Pemerintah tahun $\mathrm{t}$;

$G D_{P(t)} \quad=\quad$ Pertumbuhan PDRB sektor Pemerintah tahun $\mathrm{t}(\%)$. 


\section{2) Konsumsi Energi}

$$
\begin{aligned}
N C_{R(t)}=((1+ & \left.\left.\left(E R_{(t)} \frac{G D_{t o t}(t)}{100}\right)\right) E C_{r(t-1)}\right) \\
& +I E_{R B(t)}\left(N C_{R(t)}-N C_{R(t-1)}\right.
\end{aligned}
$$

$E C_{R(t)}=$ Konsumsi energi sektor rumah tangga tahun t;

$E R_{(t)}=$ Elastisitas konsumsi energi sektor rumah tangga tahun $\mathrm{t}$;

$N C_{R(t)} \quad=$ Jumlah pelanggan rumah tangga tahun $\mathrm{t}$

$I E_{R B(t)}=$ Intensitas Energi rumah tangga baru tahun t;

$G D_{\text {tot }(t)}=$ Pertumbuhan PDRB total tahun $\mathrm{t}(\%)$.

$E C_{I(t)}=\left(\left(1+\left(E_{I(t)} \frac{G D_{I(t)}}{100}\right)\right) E C_{I(t-1)}\right)$

$E C_{I(t)}=$ Konsumsi energi sektor industri t;

$E_{I(t)}=$ Elastisitas konsumsi energi sektor industri tahun $\mathrm{t}$;

$G D_{I(t)}=$ Pertumbuhan PDRB sektor industri tahun $\mathrm{t}(\%)$.

$E C_{B(t)}=\left(\left(1+\left(E_{B(t)} \frac{G D_{B(t)}}{100}\right)\right) E C_{B(t-1)}\right)$

$E C_{B(t)}=$ Konsumsi energi sektor bisnis $\mathrm{t}$;

$E_{B(t)}=$ Elastisitas konsumsi energi sektor bisnis tahun $\mathrm{t}$;

$G D_{B(t)}=$ Pertumbuhan PDRB sektor bisnis tahun $\mathrm{t}(\%)$.

$E C_{S(t)}=\left(\left(1+\left(E_{S(t)} \frac{G D_{S(t)}}{100}\right)\right) E C_{S(t-1)}\right)$

$E C_{S(t)}=$ Konsumsi energi sektor sosial t;

$E_{S(t)}=$ Elastisitas konsumsi energi sektor sosial tahun t;

$G D_{S(t)} \quad=\quad$ Pertumbuhan PDRB sektor sosial tahun $\mathrm{t}(\%)$.

$E C_{P(t)}=\left(\left(1+\left(E_{P(t)} \frac{G D_{P(t)}}{100}\right)\right) E C_{P(t-1)}\right)$

$E C_{P(t)} \quad=$ Konsumsi energi sektor pemerintah $\mathrm{t}$;

$E_{P(t)}=$ Elastisitas konsumsi energi sektor pemerintah tahun $\mathrm{t}$;

$G D_{P(t)} \quad=\quad$ Pertumbuhan PDRB sektor pemerintah tahun $\mathrm{t}(\%)$.

\section{Perangkat Lunak LEAP}

LEAP adalah Long-range Energy Alternatives Planning System. LEAP adalah perangkat lunak yang dapat digunakan untuk melakukan analisa dan evaluasi kebijakan dan perencanan energi [6].

\section{METODE}

A. Alur Penelitian

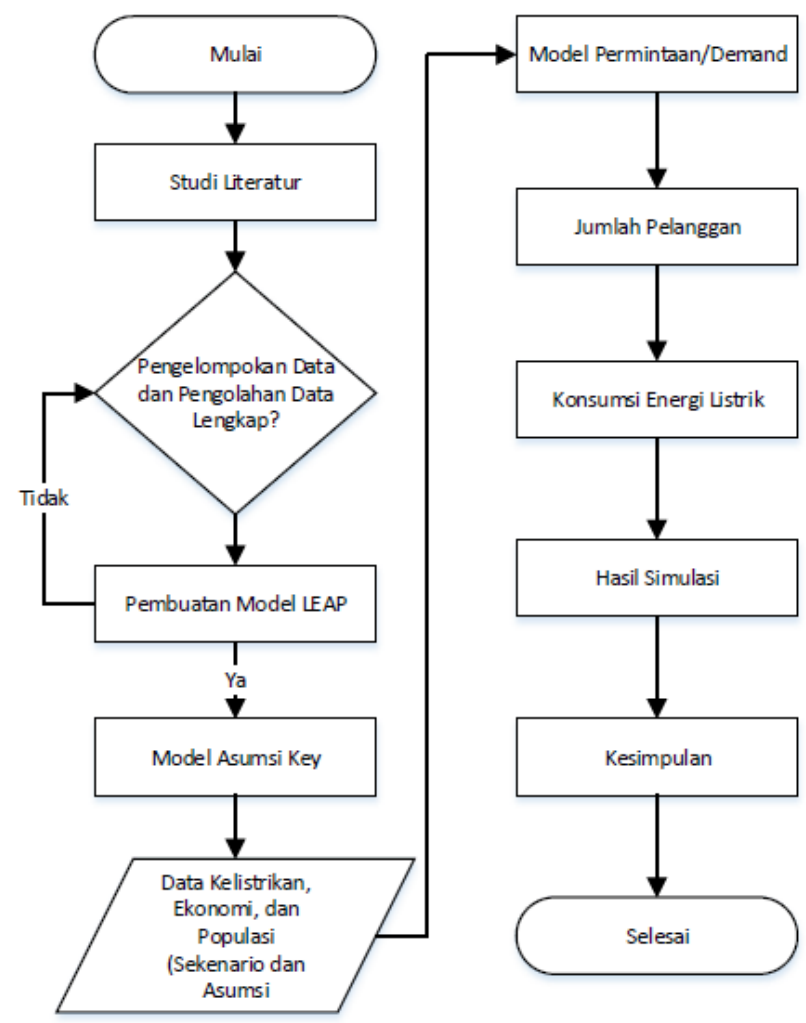

Gbr 1. Flowchart Penelitian

B. Metode Penelitian

Metode penelitian yang digunakan dalam penelitian ini adalah

1) Studi Literatur

Studi Literatur yaitu dari sumber-sumber kepustakaan sebagai landasan dalam menganalisa pembahasan yang akan dibuat dalam penyusunan tugas akhir.

2) Pengambilan Data

Pengambilan data dilakukan di Badan Pusat Statistik (BPS) Kabupaten Kuningan dan PT PLN (Persero) Area Kuningan untuk dijadikan sebagai bahan analisa pada penulisan tugas akhir ini.

3) Pembuatan Model

Pemodelan Proyeksi kebutuhan dan penyediaan energi listrik ini dengan menggunkan perangkat lunak LEAP (Long-range Energy Alternatives Planning System)

4) Hasil Analisis

Hasil Analisis yaitu proses untuk memahami data yang diperoleh dari proses pengambilan data dan pembuatan model dari perangkat lunak LEAP (Long-range Energy Alternatives Planning System).

5) Kesimpulan

Keseluruhan aspek penelitian yang terdiri dari penemuan penelitian dan pembahasan hasil penelitian.

IV. HASIL DAN PEMBAHASAN

Menghitung variabel sebagai nilai dasar di Key Assumptions (Asumsi Kunci) dalam melakukan proyeksi dengan perangkat lunak LEAP.

Berikut adalah perhitungan elastisitas energi di Kabupaten Kuningan selama 5 tahun terakhir. 
Tbl 1. Elastisitas Energi

\begin{tabular}{crrrrrr}
\hline \multirow{2}{*}{ Tahun } & \multicolumn{7}{c}{ Sektor Penggunaan (\%) } \\
\cline { 2 - 7 } & \multicolumn{1}{c}{ Bisnis } & \multicolumn{1}{c}{ Industri } & Pemerintah & \multicolumn{1}{c}{ Sosial } & Rumah Tangga & \multicolumn{1}{c}{ Jumlah } \\
\hline 2013 & 1,67 & 4,57 & 2,01 & 1,19 & 1,07 & 10,51 \\
\hline 2014 & 5,56 & 4,33 & 3,89 & 0,45 & 1,43 & 15,66 \\
\hline 2015 & 0,50 & $-2,85$ & 2,07 & 1,74 & 0,57 & 2,02 \\
\hline 2016 & $-0,15$ & 6,60 & $-0,99$ & 2,38 & 0,32 & 8,16 \\
\hline 2017 & 0,76 & 1,17 & 0,18 & 0,63 & 3,44 & 6,18 \\
\hline Jumlah & 8,34 & 13,81 & 7,17 & 6,39 & 6,83 & 42,54 \\
\hline Rata-rata & 1,67 & 2,76 & 1,43 & 1,28 & 1,37 & 8,51 \\
\hline
\end{tabular}

Berdasarkan Tbl 1, jumlah rata-rata elastisitas energi di Kabupaten adalah sebesar 8,51\%
Untuk intensitas energi di Kabupaten Kuningan selama 5 tahun terakhir adalah sebagai berikut.

Tb1 2. intensitasEnergi

\begin{tabular}{crrrrrr}
\hline \multirow{2}{*}{ Tahun } & \multicolumn{7}{c}{ Sektor Penggunaan (KWh/Pelanggan) } \\
\cline { 2 - 7 } & \multicolumn{1}{c}{ Bisnis } & \multicolumn{1}{c}{ Industri } & \multicolumn{1}{c}{ Pemerintah } & \multicolumn{1}{c}{ Sosial } & Rumah Tangga & \multicolumn{1}{c}{ Jumlah } \\
\hline 2013 & 568.629 .81 & $6.915 .330,85$ & $318.059,85$ & $75.412,59$ & $40.143,68$ & 7.917 .577 \\
\hline 2014 & $758.826,45$ & $8.576 .260,10$ & $443.721,39$ & $76.322,02$ & $45.338,00$ & 9.900 .468 \\
\hline 2015 & $705.974,74$ & $5.194 .852,86$ & $547.354,26$ & $88.130,22$ & $46.825,44$ & 6.581 .138 \\
\hline 2016 & $566.483,54$ & $8.384 .245,71$ & $487.084,28$ & $100.668,27$ & $46.349,70$ & 9.584 .832 \\
\hline 2017 & $494.774,27$ & $8.745 .581,73$ & $473.221,61$ & $100.056,74$ & $60.712,38$ & 9.874 .337 \\
\hline Jumlah & $3.094 .689,00$ & $37.816 .271,00$ & $2.269 .431,00$ & $440.590,00$ & $239.369,00$ & 43.860 .350 \\
\hline Rata-rata & $618.937,76$ & $7.563 .254,25$ & $458.886,28$ & $88.117,97$ & $47.873,84$ & 8.772 .070 \\
\hline
\end{tabular}

Berdasarkan Tabel 2, jumlah rata-rata intensitas energi adalah sebesar 8.772.070,10 kWh/pelanggan.

Perbedaan nilai antara data dari PT PLN (Persero) dengan perhitungan metode end use. Perhitungan metode end use masing-masing sektor ditentukan dengan rumus atau persamaan

\begin{tabular}{|c|c|c|c|c|c|}
\hline \multirow{2}{*}{ Selisih } & \multicolumn{5}{|c|}{ Sektor Penggunaan (\%) } \\
\hline & 2013 & 2014 & 2015 & 2016 & 2017 \\
\hline Bisnis & 15,35 & 5,99 & 9,43 & 33,36 & 35,40 \\
\hline Industri & 0,00 & 17,07 & 2,38 & 0,00 & 6,67 \\
\hline Pemerintah & 5,69 & 11,49 & 8,19 & 22,10 & 16,34 \\
\hline Sosial & 24,30 & 31,44 & 20,91 & 52,42 & 47,03 \\
\hline Rumah Tangga & 23,23 & 22,46 & 23,87 & 22,76 & 27,98 \\
\hline Jumlah & 21,30 & 20,41 & 21,87 & 19,26 & 23,96 \\
\hline \multicolumn{6}{|c|}{$\begin{array}{l}\text { dimana dalam persamaan pelanggan tersebut sektor } \\
\text { is, sektor industri, sektor pemerintah, dan sektor sosial } \\
\text { ana dihasilkan oleh faktor pelanggan dan produk } \\
\text { estik regional bruto (PDRB) dan jumlah pelanggan dari } \\
\text { PLN (Persero) sedangkan untuk sektor rumah tangga } \\
\text { silkan oleh rasio elektrifikasi, jumlah penduduk dan } \\
\text { lah orang per rumah }\end{array}$} \\
\hline
\end{tabular}

\begin{tabular}{lrrrrr} 
Tbl 4. & \multicolumn{5}{c}{ Kesalahan Persentase Konsumi Energi listrik } \\
\hline \multirow{2}{*}{ Selisih } & $\mathbf{5 0 1 3}$ & $\mathbf{2 0 1 4}$ & $\mathbf{2 0 1 5}$ & $\mathbf{2 0 1 6}$ & $\mathbf{2 0 1 7}$ \\
\cline { 2 - 6 } & 0,037 & 0,007 & 0,009 & 0,031 & 0,017 \\
\hline Bisnis & 0,017 & 0011 & 0,119 & 0,009 & 0,040 \\
\hline Industri & 0,045 & 0,041 & 0,002 & 0,031 & 0,031 \\
\hline Pemerintah & 0,019 & 0,008 & 0,041 & 0,037 & 0,015 \\
\hline Sosial & 3,808 & 2,939 & 3,992 & 3,876 & 2,763 \\
\hline Rumah Tangga & 2,748 & 1,962 & 2,656 & 2,592 & 1,985 \\
\hline \multicolumn{1}{c}{ Jumlah } & 2,65 & & & &
\end{tabular}

dimana dalam persamaan konsumsi energi listrik tersebut sektor bisnis, sektor industri, sektor pemerintah, dan sektor sosial dihasilkan oleh elastisitas energi, pertumbuhan produk domestik regional bruto (PDRB) dan konsumsi energi listrik dari data PT PLN (Persero) sedangkan untuk sektor rumah tangga dihasilkan oleh elastisitas energi, jumlah pelanggan, intenitas energi, dan konsumsi energi listrik terakhir.

Pada dasarnya kebutuhan energi suatu daerah sangat dipengaruhi oleh pertumbuhan ekonomi (PDRB) dan pertumbuhan penduduk yang selalu meningkat dari waktu ke waktu.

Pada tahun 2017 PDRB Kabupaten Kuningan harga berlaku sebesar 20.447.240 Juta Rupiah sedangkan jumlah penduduk sebesar 1.068.201 jiwa. Dengan menggunakan kedua parameter tersebut diatas maka dapat dibuat proyeksi kebutuhan energi listrik. Didalam penelitian ini, akan dianalisa lima sektor utama pengguna energi listrik yaitu sektor bisnis, sektor industri, sektor pemerintahan, sektor sosial dan sektor rumah tangga. 
p-ISSN:

e-ISSN:

A. Grafik Proyeksi Kebutuhan Energi Listrik Kabupaten Kuningan Tahun 2018-2022

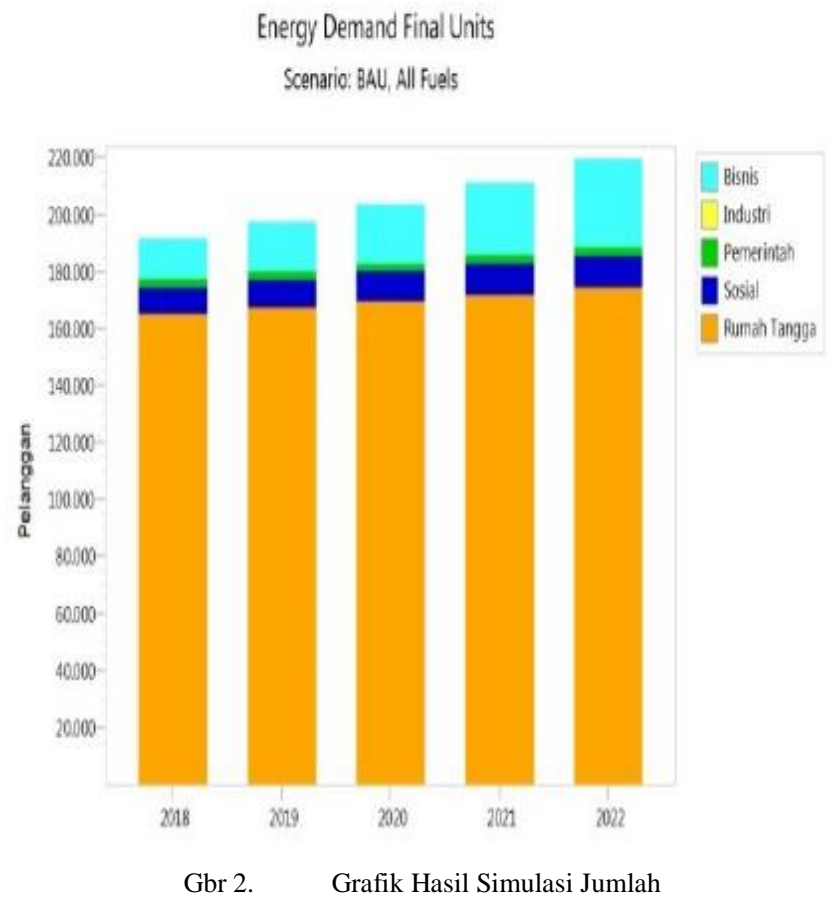

Energy Demand Final Units

Scenario: BAU, All Fuels

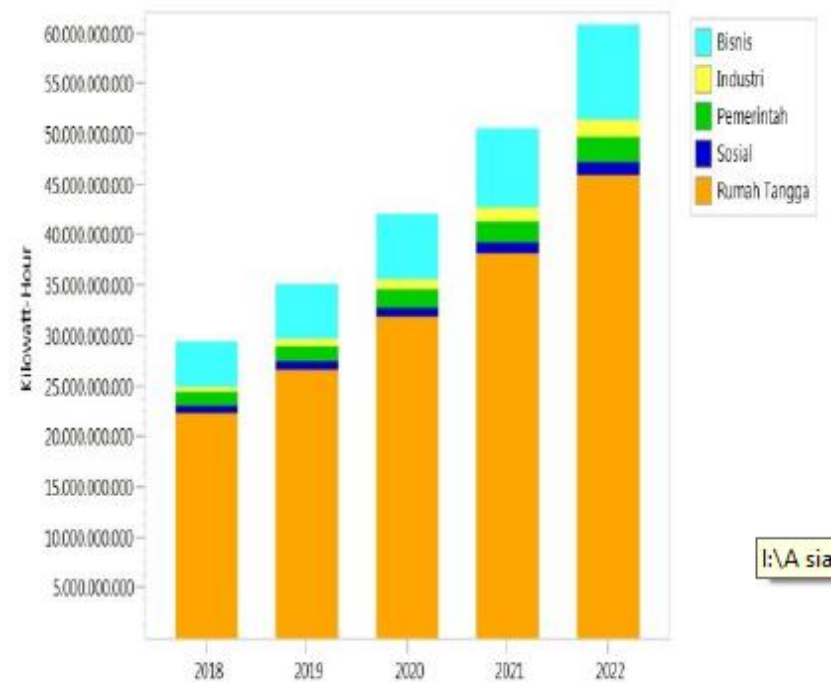

Gbr 3. Grafik Hasil Simulasi Konsumsi Energi Listrik

B. Tabel Proyeksi Kebutuhan Energi Listrik Kabupaten Kuningan Tahun 2018-2022

Tbl 5. Hasil Hasil Proyeksi Pelanggan Energi Listrik

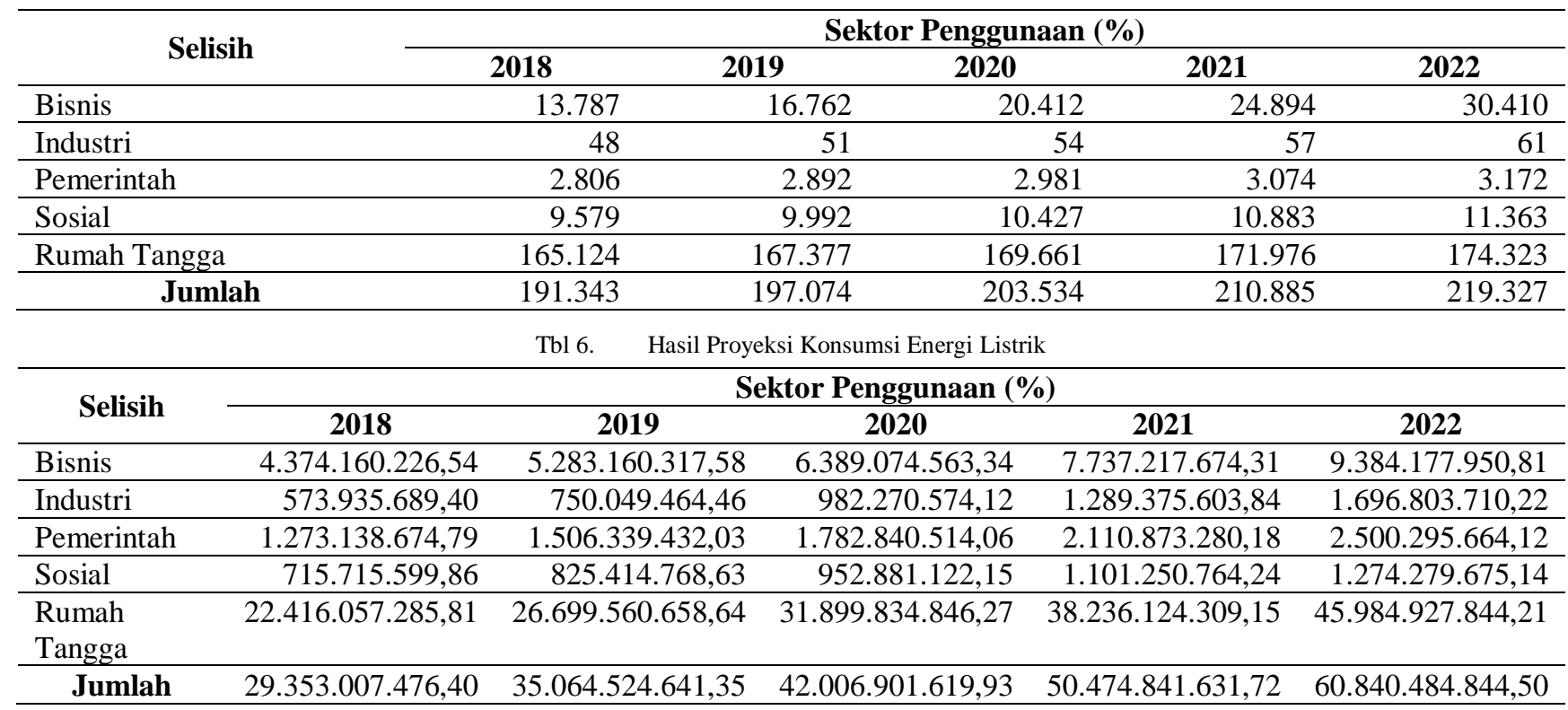




\section{ESIMPULAN}

A. Kesimpulan

1) Profil energi listrik di Kabupaten Kuningan memiliki jumlah elastisitas energi dari tahun 2013 sampai 2017 sebesar $42,54 \%$ dengan rata-rata $8,51 \%$ pertahun. Sedangkan persentase rata-rata pertumbuhan intensitas energi di Kabupaten Kuningan dari tahun 2013 sampai 2017 sebesar $56,40 \%$ pertahun. Dengan intensitas energi pada tahun 2017 sebesar 9.874.337 $\mathrm{kWh}$ /pelanggan.

2) Hasil impelementasi menggunakan metode end use lebih besar dari data aktual PT PLN (Persero) Kabupaten Kuningan. Perbedaan ini karena dalam memproyeksikan digunakan data PDRB tahun 2017 dan memperlihatkan bahwa kebutuhan energi listrik dan kebutuhan ekonomi sangat tinggi.

3) Hasil proyeksi jumlah konsumsi energi listrik dari tahun 2018 sampai 2022 adalah sebesar 60.840.484.844,50 $\mathrm{kWh}$ dengan rata-rata pertumbuhan konsumis energi listrik sebesar $8,88 \%$ pertahun, sedangkan untuk jumlah pelanggan listrik 2018 sampai dengan 2022 mencapai 219.327 pelanggan dengan rata-rata pertumbuhan sebesar $1,54 \%$ pertahun.

B. Saran

1) Perangkat lunak LEAP dapat digunakan untuk memproyekesikan energi-energi yang lain, dimodelkan sesuai dengan keinginan pengguna dan dapat juga digunakan untuk melihat dampak emisi dari energi.

2) Untuk mendapatakan hasil atau selisih dengan tingkat kebenaran dari perangkat lunak LEAP sebaiknya dibuat juga perencanaan dengan menggunkan perangkat lunak yang lain.

3) Hasil dari penelitian ini bisa digunakan sebagai pembanding dengan perencanaan yang dilakukan oleh PT PLN Kabupaten Kuningan.

\section{REFERENSI}

[1] Rajagukguk., Agus Sofyan F (2015) "Kajian Perencanaan Kebutuhan dan Pemenuhan Energi Listrik di Kota Manado". Manado: Universitas Sam Ratulangi.

[2] A. S. Pabla, Ir. A. Hadi, 1994, "Sistem Distribusi Daya Listrik", Erlangga, Jakarta, 1991.

[3] Firgiana. F, (2017), "Proyeksi Kebutuhan Dan Penyedian Energi Listrik Di Kota Tasikmalaya Menggunkan Perangkat Lunak LEAP Dengan Metode End Use". Tasikmalaya: Universitas Siliwangi.

[4] Badan Pusat Statistik. Kabupaten Kuningan, (2017), "Produk Domestik Regional Bruto (PDRB) Kabupaten Kuningan Menurut Lapangan Usaha 2012-2017'.

[5] Deryanus Kassa. (2015), "Ketersediaan Energi Listrik Sulawesi Utara Sampai Tahun 2020". Manado : UNSRAT.

[6] M. E. Wijaya S.T., M.Sc, Dr. Eng. M. K. Ridwan S.T., M.Sc., "Modul Pelatihan Perencanaan Energi Menggunakan LEAP”, Jurusan Teknik Fisika Universitas Gadjah Mada, Yogyakarta, 2009.

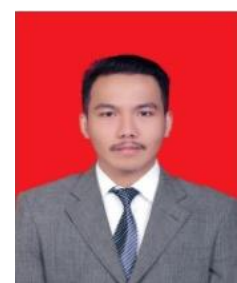

\section{BIOGRAFI PENULIS}

Gugun Muliawandana, lahir di Bekasi pada tanggal 23 Juli 1996. Saat ini sedang menempuh pendidikan sarjana di Jurusan Teknik Elektro, Universitas Siliwangi. Bidang penelitian yang ditekuni saat ini yaitu Sistem Tenaga. 